\title{
La transparencia, política del engaño
}

\author{
Entrevista a Gustavo Dessal
}

\author{
ELP-Madrid
Juan Pablo Duarte*, Lorena Beloso, Juan Ernesto Brodsky, Eugenia Destéfanis, Gigliola Foco y Eugenia Castro

Universidad Nacional de Córdoba, Argentina

\begin{abstract}
A mediados de Agosto nos encontramos vía Zoom Juan Pablo Duarte, Eugenia Destéfanis, Juan Brodsky, Eugenia Castro, Gigliola Foco y Lorena Beloso - miembros del Equipo Editorial de Ética E Cine Journal - con el psicoanalista y escritor Gustavo Dessal. Miembro de la Escuela Lacaniana de Psicoanálisis y de la Asociación Mundial de Psicoanálisis. Formado en Buenos Aires y París, reside en España desde 1982, donde ejerce su práctica clínica hace más de treinta años. Ha dictado cursos y conferencias en Argentina, Brasil, España, Francia, Italia e Inglaterra. Es autor de numerosos libros y publicaciones sobre psicoanálisis, como así también de relatos y novelas.

Fueron principalmente los escritos de "El manicomio global" - su página de Facebook - que bajo el título de "Reclusiones", "Informe sobre lo inverosímil”, "Diario del asombro", “Corónica del mundo exterior”, abordaron exhaustivamente la temática de la pandemia a partir de una lectura psicoanalítica de sus efectos en el mundo, y nos causaron a entrevistarlo para esta edición del Journal: Ética en tiempos de Pandemia. Plasmamos a continuación lo conversado en dicho encuentro.
\end{abstract}

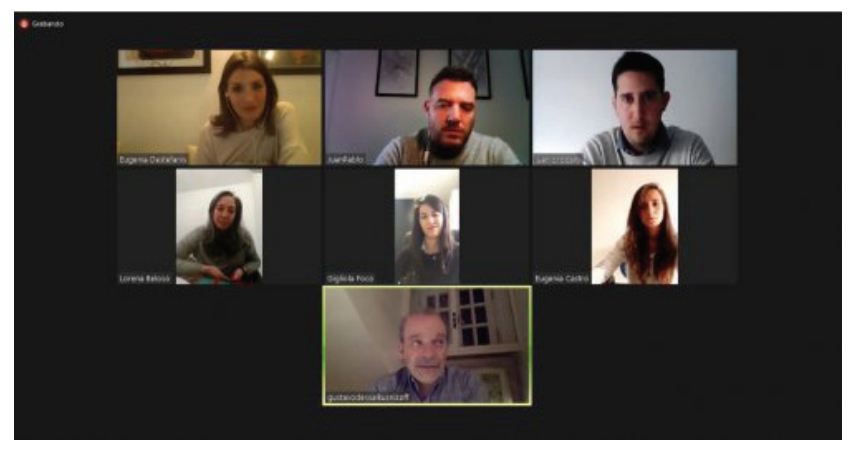

Eugenia Destéfanis: Antes de comenzar le agradezco por aceptar la invitación a la entrevista. Una de las preguntas que querría hacerle es partir de la lectura de su texto "La infección es biológica. La pandemia es política”, donde retoma la referencia de Lacan acerca de los "dioses oscuros", y plantea que los "dioses actuales no son nada oscuros. Son transparentes como el agua de antaño" ¿Podría decirnos algo más sobre esto? ¿De qué dioses se trata en la época actual?

G.D.: Bueno, la diferencia entre lo biológico de la epidemia y lo político de la pandemia me parece una distinción que es importante, no es algo que se me haya

juanpduarte2@eco.uncor.edu ocurrido solamente a mí, está en el pensamiento de mucha gente. Una cosa es lo real biológico y otra cosa es el manejo que de eso se hace. Este manejo implica distintos aspectos, el impacto que eso produce a nivel del sujeto en tanto uno, a nivel de la colectividad y también desde el punto de vista de cómo cada país, cada gobierno, cada comunidad gestiona la incidencia de ese fenómeno biológico. Hemos visto que efectivamente a lo largo de que todo esto comenzó hubo distintas respuestas. Más o menos dentro de la variedad de las respuestas creo que ha habido dos grandes categorías que se corresponden con el aspecto más político, aquellos países que se inclinaron en la elección entre la bolsa y la vida, se inclinaron por proteger fundamentalmente la vida a costa de los sacrificios que hubiera que hacer respecto de la bolsa, y aquellos que de entrada consideraron que había que apostar a la bolsa. Vamos a decir que no lo podemos considerar desde un punto de vista estrictamente canallesco. No es tan sencillo. Creo que hay que situar eso en un contexto. Esa distinción que al principio fue muy celebrada, los países que eligieron proteger la vida y aquellos que decidieron poner por encima de todos los valores la economía, con el paso del tiempo se fue verifi- 
cando una cuestión y es que no era tan sencillo establecer ese maniqueísmo, los buenos que protegen la vida y los malos. Claro, todos los países fueron dándose cuenta en la medida en que esto se empezaba a prolongar y no se resolvía con la rapidez que imaginábamos que iba a ocurrir. Sucede que se empieza a verificar que incluso aquellos países que apostaron por defender fundamentalmente la salud de la población tienen que empezar a hacer ciertas concesiones.

Por otra parte, respecto a que los dioses no son tan oscuros, es porque vivimos bajo el lema de la transparencia. Que todo quede expuesto a la luz. Prácticamente ya nada ni nadie tiene derecho a la más mínima parcela de intimidad. Todo tiene que quedar expuesto a la mirada. Eso no significa que sea cierto, hay muchas cosas que por supuesto permanecen ocultas. Pero lo que impera, por lo menos en el discurso del paradigma contemporáneo, es que efectivamente todo tiene que darse a conocer. Todo se tiene que saber. Nada puede permanecer en la privacidad o escondido de la mirada que escruta, que es, bueno, The Big Force, se llama en Estados Unidos a las cuatro grandes compañías: Facebook; Google; Apple y Amazon. Los cuatro grandes. Los cuatro dioses que hoy en día dominan verdaderamente, que tienen una cuota de poder impresionante. $Y$ que, efectivamente, hacen de la transparencia una política totalmente engañosa. Transparencia para ciertas cosas y oscuridad para muchas otras.

Lorena Beloso: Retomo que Usted distingue posiciones opuestas en las políticas de gestión en relación a ese real biológico y dice, la bolsa o la vida; mencionó el lema de la transparencia y pienso en aquello que, aunque se intente, no se puede disimular. Esto me remite a una pregunta que quería hacerle. En uno de sus escritos, "Corónicas del mundo exterior 3", hace referencia a las ideas megalomaníacas contemporáneas, ante la ausencia de coordenadas éticas, y los efectos subjetivos que eso genera, ¿̨podría explayarse más al respecto?

G.D.: No recuerdo el contexto en el que dije eso pero creo suponer que me refería a que nos bastó un virus, un elemento absolutamente microscópico e invisible que dejó en ridículo todas las noticias pseudocientíficas que en los últimos diez años más o menos nos vienen bombardeando, bombardeando desde plataformas con un gran prestigio, donde se nos anuncia que estamos prácticamente a punto de erradicar las en- fermedades más importantes, que estamos a punto de conquistar una duración, un promedio de vida de ciento veinte, ciento treinta, ciento cuarenta años; dicho además de una manera totalmente irresponsable puesto que todo eso desconoce - en el caso de que fuese cierto, cosa que se ha demostrado que es falso - todas las consecuencias demográficas, económicas, éticas, que todo eso tendría. Entonces, todos de alguna manera hemos participado en comprar un discurso donde lo que se ofrecía, la oferta era un producto, una mercancía que es objeto de avidez desde que existe la historia de la humanidad que es la idea de la inmortalidad, la promesa de que por fin gracias a la tecnología estamos prácticamente a punto de conquistar todo eso. Ya se sabía que todo eso era falso. Cuando digo que ya se sabía me refiero a que hay muchísimos estudios, voces, científicos respetables que han alzado su voz para mostrar que todo eso era una verdadera estafa. Pero claro, estas compañías que promocionan estas ideas tienen tal capacidad mediática y de expansión, que la gente que tiene un discurso sensato y veraz no puede competir con todo eso, no puede competir con el carácter viral que cobra toda esa información pseudocientífica que además está auspiciada por compañías importantes.

The alphabet, es la división de Google que se dedica a todos los proyectos que tiene que ver con muchos otros aspectos que no son el de la comunicación. Por ejemplo, se ocupa de todo lo que es biología humana, investigaciones en biología, investigaciones en tecnologías desde el famoso coche sin conductor hasta investigaciones en nanotecnología. Una compañía que es subsidiaria, pertenece a Google. Ellos han dividido la compañía madre en varias ramas. Esta que hoy en día es posiblemente la rama más importante maneja un presupuesto de cientos de miles de millones de dólares dedicados a todo esto. Cuando uno ve la gente que se contrata, los estudios que realizan, la inversión de dinero, es muy difícil que uno no crea que todo lo que se promueve bajo esa plataforma no sea cierto. Ahora se ha demostrado que lo único más o menos verídico que Google ha podido ofrecer en relación a este tema de la pandemia ha sido la creación junto con Apple de una aplicación de rastreo, lo más divertido es que prácticamente no ha sido aceptada en casi ningún lugar del mundo. Una aplicación de rastreo de la pandemia es una cosa absolutamente elemental, se fabrica, se crea en una semana. Ni siquiera dos compañías monstruos como Google y Apple trabajando juntas han creado alguna aplicación que despierte algún interés. $\mathrm{O}$ sea, que después de todo lo que se promociona asegurando que 
tocábamos la inmortalidad, resulta que no han podido ofrecer desde el punto de vista de sus soluciones tecnológicas, prácticamente nada.

Gigliola Foco: En ese punto, sobre la supuesta idea de que estamos tocando la inmortalidad, una pregunta: en una de sus publicaciones donde hace referencia al furor que han producido las películas de zombies en los últimos tiempos, en relación al retorno de monstruos que dábamos por extinguidos como los fascistas, los nazis, los franquistas ¿Qué retorna junto con el despertar de estos caminantes?

G.D.: Había leído una publicación que se hace todos los años en Estados Unidos, de un conjunto de expertos, técnicos que asesoran hoy al equipo de Trump como antes lo hicieron al de Obama. Gente que se limita a hacer una tarea de rastreo y de detección de ciertos problemas, puede tener un sesgo político. Pero este comité asesor se dedica todos los años a hacer una detección sobre cuáles son las amenazas más importantes que rondan en el planeta. Este año, consideran que, mucho más que cualquier catástrofe natural, mucho más que la pandemia, es el surgimiento del neonazismo. Se trata del retorno de los zombies, de estos muertos que no han muerto. Comprobamos que, cosas que parecían extinguidas, no se han extinguido y retornan, en distintos contextos. El libro que tuve el placer de publicar con Zygmunt Bauman se tituló El retorno del péndulo, título que yo sugerí porque extraje, de uno de los correos electrónicos que él me había enviado, ese sintagma. Él me decía que, después de haberse dedicado muchos años a la licuefacción del mundo, tenía que admitir que estaba empezando a ver los síntomas de una especie de resolidificación del mundo. Los valores que se habían disuelto, volvían y de la peor manera. En España en concreto, Franco no ha muerto, el franquismo sigue vivo en el tejido social.

Juan Pablo Duarte: Nuestro título para el próximo número del Journal plantea una pregunta, una hipótesis y es que la pandemia nos abriría nuevos interrogantes, nuevos desafíos a nivel de la ética a quienes nos formamos en psicoanálisis. Mi pregunta es sobre esa hipótesis que manejamos para este número ¿̨ué opinión le merece eso, la pandemia nos introduce nuevos temas, nuevos desafíos, nuevas discusiones en el campo de la ética a los psicoanalistas?
G.D.: Sí, yo creo que todo esto ha abierto una cantidad inmensa de interrogantes, no sólo en el campo del psicoanálisis. Me parece que todos los saberes quedan profundamente cuestionados, interrogados, sacudidos y también estimulados por el surgimiento de todo esto. Dentro del campo específico del psicoanálisis, uno de los aspectos donde más nos hemos visto tomados es por el hecho de que se trata de una práctica que, a diferencia de otras que sin lo presencial son absolutamente imposible de ser llevarlas a cabo, como por ejemplo una intervención médica, nuestra práctica tiene la característica que - hasta ahora no habíamos caído en ello porque no nos habíamos visto en la tesitura de una situación semejante - algo de lo que hacemos se puede de alguna forma transportar a lo virtual. Digo algo porque en ese sentido tenemos que ser prudentes. Evidentemente no es lo mismo. Como no es lo mismo tampoco la enseñanza a través de lo virtual, por ejemplo. Es mejor que los niños tengan alguna clase de enseñanza a través de internet a que no tengan nada, es mejor que podamos continuar trabajando con los pacientes antes de que se vean interrumpidos los tratamientos.

Es una de las cuestiones que toca ahora tratar de pensar, sin apresuramientos, sin sacar conclusiones precipitadas. Creo que para poder sacar conclusiones que tengan una validez doctrinal tiene que pasar mucho tiempo, tiene que haber mucha casuística, tenemos que poder corroborar muchas cosas. Lo que de momento sabemos es que hemos podido hacer algo, que lo que se ha podido hacer es bastante digno, que la gente ha podido tener acceso a continuar de esta manera. En términos generales, se ha sentido bastante satisfecha y bastante conforme con la posibilidades de trabajar de esta manera. Por lo tanto, evidentemente esto que empezó como una contingencia que había que resolver, ahora que sucede, hay que preguntarse qué va a quedar de todo esto, qué se va a mantener, si es necesario que algo se mantenga, si esto va a imponer una realidad nueva. Personalmente, sospecho que sí. Evidentemente, después de esto que ha sucedido veo un poco difícil que sea solamente una especie de equipo que uno rompe el cristal y lo utiliza solo en situaciones de urgencia. Creo que esto de alguna manera se va a incorporar en parte a nuestra práctica. Personas que pueden solicitar un análisis, que por razones geográficas no pueden desplazarse, o porque viven en lugares donde no encuentran un analista en la región, o no encuentran a un analista de determinada orientación de determinada escuela, lacaniana o cualquier otra, personas que efectivamente por algún motivo han sido 
desplazadas al extranjero y quieren continuar su análisis. Muchas de estas cosas ya existían antes. Muchísimos analistas vienen llevando a cabo experiencias de este tipo solo que, por alguna razón, que sinceramente me gustaría mucho poder investigar, ha habido un pudor alrededor de todo esto que ha impedido que se pudiera hablar más libremente de este tema. Esa especie de secreto a voces. De eso no se hablaba. Hay otro de los grandes temas de los cuales no se habla. El dinero. Esa cosa etérea, misterios. Tampoco se habla de eso. Creo que si no hubiese regido esa especie de pudor o autocensura hubiera sido muy útil porque esta situación del coronavirus nos hubiera encontrado con una discusión previa y con una serie de elementos aunque sea provisionales para pensar un poco qué hacer con todo esto. Es hora de empezar, con la menor cantidad de prejuicios, a discutir sobre todo esto, sin extralimitarse en un sentido ni en el otro, sin pensar que el único análisis posible, puro y válido es el que se hace frente a frente o en persona y que todo lo demás no es válido. Ni lo contrario, no entrar en la idea de que es absolutamente igual hacerlo de esta manera que en persona.

Creo que hay que tratar de investigar esto. Nos da la posibilidad de investigar, de estudiar muchos conceptos, de repensarlos; qué es la presencia, qué es lo corporal en psicoanálisis. Se dice mucho qué pasa con los cuerpos, como si el cuerpo no estuviera implicado en esto. Yo pongo de ejemplo al cine. Si uno cree que al ver una película el cuerpo del espectador no está implicado en la situación entonces yo no sé cómo llamar a lo que uno experimenta cuando ve una película donde se siente verdaderamente conmovido, cuando ver una película es un acontecimiento. Uno puede llorar, reírse hasta que le duele la panza, descomponerse, sufrir un ataque de angustia, salir y experimentar una tristeza que no sabe de dónde sale. Todo eso que se moviliza si no se produce porque el cuerpo está presente, qué es. Entonces, decir que a través de internet el cuerpo no existe me parece una observación un poco banal.

Eugenia Castro: En ese sentido, pensando en relación al progreso Usted escribía en "Corónica del mundo exterior 5" que "depositamos una excesiva confianza en el progreso, confianza que solo puede sostenerse en el olvido de la verdad y que las Pandemias se olvidan". En 1976 Lacan plantea una crítica respecto a la idea de progreso y "El malestar en la cultura" fue el significante freudiano para hacer cierta alusión al respecto
¿De qué manera puede pensarse en la actualidad? ¿Qué rasgo diferencial puede ubicarse en esta época con la situación que se está atravesando?

G. D.: Hay un historiador, que escribe una obra magníficamente relatada. Se llama El jinete pálido. Es una historia contada sobre las pandemias. Es un ensayo, pero tiene una forma un tanto novelada y hay una serie de datos históricos interesantes. Ahí hay una observación que es realmente muy notable: las guerras dejan huella en la memoria colectiva mientras que no sucede lo mismo con las pandemias. Éstas se olvidan con una velocidad impresionante. Hay muchas razones e hipótesis al respecto. Por una parte, está el hecho de que las pandemias obedecen a un enemigo que es invisible, que es muy difícil saber dónde está y donde no hay verdaderamente, lo que en otra época se llamaba, un "frente de batalla". Y, por otro lado, la guerra tiene una dimensión ideológica y, por lo tanto, un carácter heróico que la pandemia no tiene. Dicho de un modo un tanto vulgar, las pandemias nos matan como moscas, nos aplastan como cucarachas, mientras que la guerra se puede disfrazar de elementos que la vuelven un poco romántica. Morir por un ideal, por una causa, por defender a la Patria. Argumentos, independientemente de lo falaces que puedan ser, pero hay toda una argumentación por la cual la guerra se puede disfrazar de un sentido. En algún momento, las pandemias eran como un castigo divino y se encontraba un sentido. A partir del Renacimiento -cuando Dios dejó de existir para el colectivo, es decir, como algo que explicara alguna cosa- eso se cayó y la gente ya no se tragaba ese cuento, era imposible atribuir ningún sentido, era morir por morir. Verdaderamente era la confrontación de un sinsentido radical. Por lo tanto, cambió totalmente la concepción. Entonces, mientras la guerra siguió manteniendo la posibilidad de hallar algún sentido para la gente, aunque sea una atrocidad, ya sea porque somos víctimas de la maldad del vecino o porque el vecino es algo inmundo que hay que exterminar, es decir, todos los argumentos, bueno, le dan una narrativa a la guerra. La pandemia no tiene ninguna narrativa. $\mathrm{O}$ sea, es confrontarse con algo ante lo cual nos sentimos totalmente impotentes, no sabemos qué hacer. Siempre existe la posibilidad de tratar de encontrar, de alguna manera, por lo menos, alguna víctima propiciatoria de ser factible de acusar de ser factor. Hoy en día, pongo el caso, ya sabemos que esto pasa en muchos lugares del mundo.

¿Quiénes han traído el coronavirus? Los inmigrantes, por supuesto, los extranjeros. Aquí, en España, en 
las zonas agrícolas hay muchos temporeros que son inmigrantes que son contratados para realizar diferentes tareas. Recoger frutas, verduras. Tareas tremendas, la gente vive en condiciones inhumanas. Es probable que, en esas condiciones de hacinamiento, de falta de higiene, de falta de agua corriente, esas personas a lo mejor son un colectivo que han estado más expuestos, menos protegidos, sin recursos, sin barbijos, ni alcohol, ni gel, ni agua corriente. Bueno, es probable que esa gente haya contribuido en parte, pero de la misma manera que durante la peste negra que por supuesto ¿quiénes eran los primeros a quienes se le atribuía de haber traído la pandemia? Los judíos. Es decir, siempre ha existido alguien a quien uno le pueda echar la culpa. Pero, así y todo, ese discurso de quien ha traído el virus ¿quién es el culpable? no llega a tener la consistencia narrativa o representativa que tiene la guerra. Por eso, las pandemias son cosas que se olvidan más rápidamente. Es decir, es probable, vamos a verlo, porque nosotros hemos sido testigos de un momento histórico que a lo mejor la generación de nuestros padres no lo conoció, yo no conocía una cosa semejante. No sé ustedes dentro de diez, quince años cómo van a recordar esto mismo, si lo van a transmitir, o si será una cosa que alguien un día en una reunión va a decir: "aaah, ¿te acordás?" Seguramente, la dimensión, la importancia que todo esto tuvo se va a relativizar, se va a ver como una cosa mucho menor de lo que realmente fue. Habrá que esperar para ver cómo se desarrolla.

De todas maneras, Eugenia, me parece que hay algo que no se si llegué a captar de tú pregunta. Quizá si pudieras precisar un poco más lo que tratabas de preguntarme porque me parece que apuntaba a algo más.

\section{Eugenia Castro: Sí, era acerca de la extensión cada vez más dura de los procesos de segregación, algo que La- can advierte ya en 1967 y que tal vez también puede pensarse en esta circunstancia, como algo característi- co de la actualidad.}

G. D.: Ahora estoy recordando algo que dijiste al principio y que es importante. El tema del progreso, qué pasa con la cuestión del progreso. Lacan lo dice en uno de los primeros seminarios: Freud, era antiprogresista, es decir, no creía en el progreso. Fue Stefan Zweig, su contemporáneo, quien dijo que la cultura era apenas una fina capa de polvo que en cualquier momento podía ser barrida con el más mínimo viento y es verdad, a esto lo podemos ver. Bueno, claro que hay progreso en ciertos aspectos que son indudables. Es decir, ¿ha progresado la medicina? Sí, ¿ha progresado la posibilidad de mejorar las condiciones de vida en muchos lugares en el mundo? Sí. Desde el momento en que, al menos desde el punto de vista legal, la esclavitud se ha erradicado o está prohibida. Digamos, aunque en la oscuridad existan formas de esclavitud. Pero bueno, al menos no se admite legalmente ¿Eso implica un progreso? Desde luego. Es decir, en muchos terrenos obviamente no podemos dejar de reconocerlo. Que existan antibióticos, es un progreso. Que exista la anestesia, es un progreso. Que algo en el orden de los derechos humanos haya avanzado, es un progreso. Lo que pasa es que todo eso, al mismo tiempo, es muy frágil. ¿Qué quiere decir? Que eso puede regir durante un tiempo pero que todo ese progreso que es indiscutible, no afecta algunos aspectos de la condición humana que no progresan, que se mantienen. Y el psicoanálisis se ocupa fundamentalmente de eso. El psicoanálisis se ocupa básicamente de lo que no cambia. De lo que permanece inmutable a lo largo de la historia. Pueden cambiar algunas incidencias históricas, culturales que ejercen cierta influencia. Pero esa es una influencia fundamentalmente quizá en los semblantes, en lo imaginario.

Obviamente, el modelo de masculinidad en el mundo occidental contemporáneo posiblemente ha cambiado algo a consecuencia de toda una serie de movimientos, de discusiones y debates, etc. Ahora, ¿eso cambia?, desde el punto de vista de cómo el psicoanálisis aborda eso. Es decir, los resortes inconscientes de cómo se constituye la posición masculina, el acceso a la virilidad, las identificaciones. Eso, ¿hasta qué punto está verdaderamente afectado, ha cambiado? ¿La pulsión de muerte es algo que se va progresivamente superando mediante la educación, la cultura, la discusión, los debates internacionales?

Ayer vi una película maravillosa con mi nieto, Zootopia (Disney, 2016). Yo soy de la idea de que las películas de dibujos animados, precisamente las actuales, son muy buenas, están hechas por directores extraordinarios, por gente que tiene una capacidad de transmitir mensajes interesantísimos porque muchas de esas películas están dirigidas no solamente a los niños, sino que a veces el mensaje más importante es para los adultos. Se las recomiendo, porque es maravillosa. El argumento es que Zootopia es una ciudad, una megalópolis impresionante, donde viven en armonía y en paz todos los animales. Fundamentalmente, los animales se dividen en 
dos grandes grupos: las presas y los depredadores. En esa ciudad las presas y los depredadores han encontrado una armonía. Los depredadores han renunciado definitivamente a sus instintos bárbaros, ya no se comen a las presas, todo el mundo es feliz y la ciudad se divide en zonas climáticas para que vivan, los animales del desierto, los animales de la jungla, los animales del frío. Hasta que ocurre un acontecimiento que altera la armonía paradisíaca que reinaba en esa ciudad donde se creía que los instintos bárbaros habían sido erradicados. De pronto, algo sucede que se altera el equilibrio de esa comunidad y aquello que se creía erradicado vuelve de una manera misteriosa. Entonces, todo el argumento consiste en tratar de averiguar qué ha pasado, cómo ha ocurrido eso. La película es extraordinaria porque más allá del contenido manifiesto, tomemoslo como si fuera un sueño, el mensaje que se transmite es que uno tiene que también poder convivir con lo diverso y que lo diverso no necesariamente es armónico. Que hay una cierta disparidad en el lazo social que es inextinguible, que hay que poder hacer con eso. Que el psicoanálisis tiene un cierto saber sobre eso y tiene una práctica que puede introducir a nivel del uno por uno cierta rectificación.

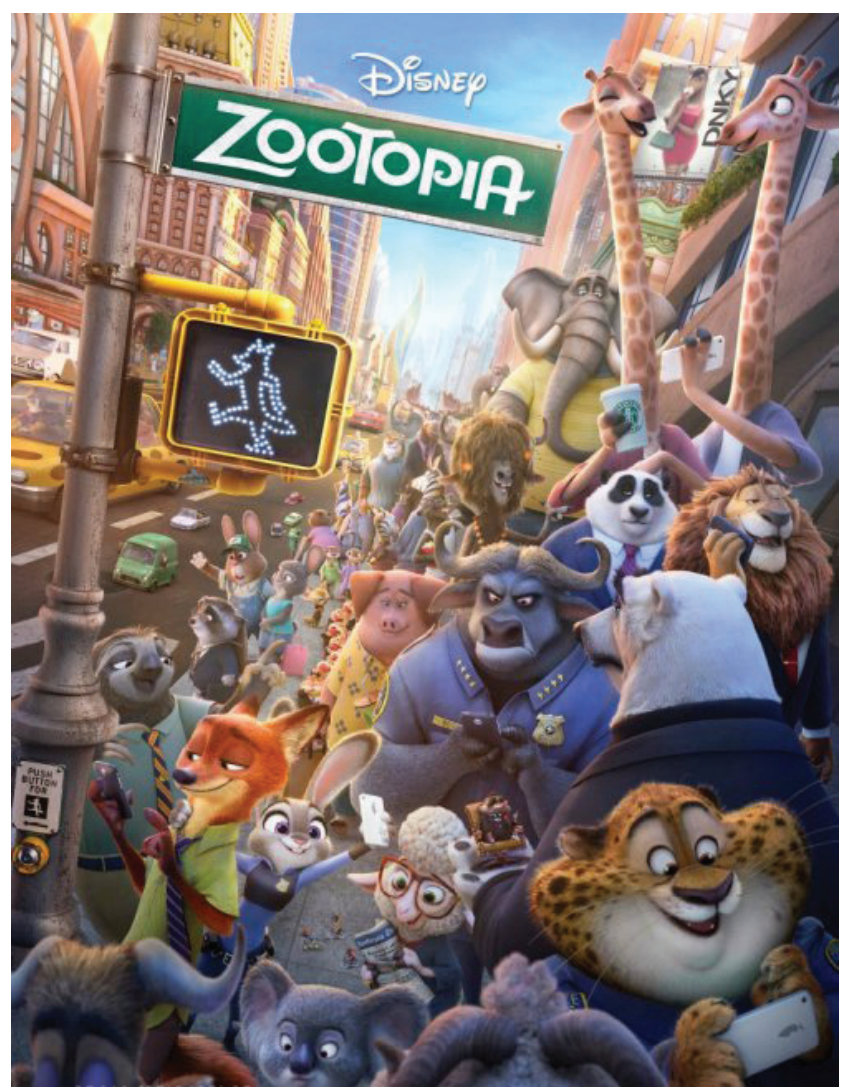

